contact of detegent molecules with each other. As the detergent concentration continues to increase, the transfer free energy increases until the vesicle is eventually destroyed.

\section{ACKNOWLEDGMENTS}

I thank Prof. I. Horikoshi for his continuous support on this work and M. Fukuda and M. Funakawa for their experimental assistance.

Registry No. OG, 29836-26-8; $\mathrm{Cl}^{-}, 16887-00-6$.

\section{REFERENCES}

Allen, T. A., Romans, A. Y., Kerecret, H., \& Sergest, J. P. (1980) Biochim. Biophys. Acta 601, 328-342.

Almog, S., Kushnir, T., Nir, S., \& Lichtenberg, D. (1986) Biochemistry 25, 2597-2605.

Bartlett, G. R. (1959) J. Biol. Chem. 234, 466-468.

Brunner, J., Skrabal, P., \& Hauser, H. (1976) Biochim. Biophys. Acta 455, 322-331.

Hauser, H., Oldani, D., \& Phillips, M. C. (1973) Biochemistry 12, 4507-4517.

Kramer, R., \& Heberger, C. (1986) Biochim. Biophys. Acta 863, 289-296.

Martin, D. W., \& Ueno, M. (1985) Biophys. J. 47, 154.

Mimms, L. T., Zampighi, G., Nozaki, Y., Tanford, C., \& Reynolds, J. A. (1981) Biochemistry 20, 833-840.

Nozaki, Y., Lacic, D. D., Tanford, C., \& Reynolds, J. A. (1982) Science 212, 377-367.
O'Connor, C. J., Wallace, R. G., Iwamoto, K., Taguchi, T., \& Sunamoto, J. (1985) Biochim. Biophys. Acta 817, 95-102.

Ollivon, M., Eidelman, O., Blumenthal, R., \& Walter, A. (1988) Biochemistry 27, 1695-1703.

Rhoden, V., \& Godin, S. M. (1979) Biochemistry 18, 4173-4176.

Ruiz, J., Goni, F. M., \& Alonso, A. (1988) Biochim. Biophys. Acta 937, 127-134.

Schurtenberger, P., Mazer, M., Waldvogel, S., \& Kanzig, W. (1984) Biochim. Biophys. Acta 775, 111-114.

Schurtenberger, P., Mazer, M., \& Kanzig, W. (1985) J. Phys. Chem. 89, 1042-1049.

Shinoda, K., Yamanaka, T., \& Kinoshita, K. (1959) J. Phys. Chem. 63, 648-650.

Tanford, C. (1980) The Hydrophobic Effect, 2nd ed., p 68, Wiley, New York.

Toyoshima, Y., \& Thompson, T. E. (1975) Biochemistry 14, $1525-1531$.

Ueno, M. (1986) Med. Drug. J. 22, 2045-2051.

Ueno, M. (1987) Biochim. Biophys. Acta 904, 140-144.

Ueno, M., Tanford, C., \& Reynolds, J. A. (1984) Biochemistry 23, 3070-3076.

Ueno, M., Tanaka, N., \& Horikoshi, I. (1989) J. Membr. Sci. 41, 269-279.

Zumbuehl, O., \& Weder, G. (1981) Biochim. Biophys. Acta $640,252-262$.

\title{
Rotational Motion of Yeast Cytochrome Oxidase in Phosphatidylcholine Complexes Studied by Saturation-Transfer Electron Spin Resonance
}

\author{
Piotr Fajer, $\$, \delta$ Peter F. Knowles, $"$ and Derek Marsh ${ }^{*, \ddagger}$ \\ Max-Planck-Institut für biophysikalische Chemie, Abteilung Spektroskopie, D-3400 Göttingen, Federal Republic of Germany, \\ and Astbury Department of Biophysics, University of Leeds, Leeds, LS2 9JT, U.K. \\ Received December 27, 1988; Revised Manuscript Received March 8, 1989
}

\begin{abstract}
Cytochrome oxidase from yeast has been covalently labeled with a nitroxide derivative of maleimide and reconstituted in lipid-substituted complexes with dimyristoyl-, dioleoyl-, or dielaidoylphosphatidylcholine. The rotational mobility of the enzyme in the complexes has been studied as a function of temperature and time, and of lipid/protein ratio, using saturation-transfer electron spin resonance spectroscopy. For complexes with dimyristoylphosphatidylcholine, the rotational mobility of the protein decreases abruptly below the gel-to-fluid-phase transition. This change is accompanied by a lateral segregation of the protein, as seen by freeze-fracture electron microscopy, and by an increase in the activation energy for the enzymatic activity. A time-dependent decrease in the rotational motion of the protein is observed on incubating at temperatures in the fluid phase of the lipid. This corresponds with a time-dependent loss of enzyme activity observed on incubation at temperatures in the fluid phase, but not at temperatures in the gel phase, over a period of $3 \mathrm{~h}$. The rotational mobility decreases with increasing protein concentration in the complexes, both in the fluid and in the gel phases. The dependence of the protein mobility on lipid/protein ratio can be interpreted quantitatively in terms of the effect of increased random protein-protein contacts in the fluid phase. The maximum limiting rotational correlation time for the protein diffusion at high lipid/protein ratios in the fluid phase is $\tau_{R_{1}} \approx 25 \mu \mathrm{s}$, suggesting that the protein is present as either a monomer or more probably a dimer in the reconstituted membrane.
\end{abstract}

C ome $c$ oxidase is the terminal member (complex IV) of the mitochondrial respiratory chain, being responsible for

\footnotetext{
Max-Planck-Institut für biophysikalische Chemie.

I Present address: Department of Biochemistry, University of Minnesota Medical School, Minneapolis, MN 55455.

"University of Leeds.
}

the transfer of electrons from cytochrome $c$ to molecular oxygen, with concomitant proton pumping. The enzyme is a multisubunit integral protein situated in the inner mitochondrial membrane. The relative orientation and proximity of this enzyme complex to that of cytochrome $c$ reductase, the preceding member (complex III) of the electron-transport chain, is a factor of considerable relevance to the function of 
the chain, as indeed is the proximity and interaction with other mitochondrial proteins, especially the proton ATPase.

It has been proposed that, since the mitochondrial inner membrane is in a fluid state, all membrane proteins and redox components are in constant, independent diffusive motion (Hackenbrock et al., 1986). Rates of electron transfer and the efficiency of ATP synthesis could then depend on the mobility of the membrane proteins that would be required to achieve the necessary proximity and correct relative orientations of the various redox partners.

One approach to the analysis of these factors is to study the rotational mobility of the protein complex, a parameter which is also sensitive both to the aggregation state of the protein and to protein-protein interactions within the membrane (Kawato et al., 1980, 1982). This we have done using purified cytochrome oxidase from yeast mitochondria reconstituted with different phosphatidylcholine species of defined chain length and degree of unsaturation. The gel- to fluid-phase transition of these lipids makes it possible to compare results for different mobility and aggregation states of the enzyme, simply by varying the temperature. Particular attention has been devoted to the dependence of the rotational mobility on protein concentration, and to the time- and temperature-dependent aggregation. It was found that the latter could be related to the effects on enzymatic activity.

\section{Materials AND MethodS}

Chemicals. Dimyristoylphosphatidylcholine (DMPC) ${ }^{1}$ was from Fluka (Buchs, Switzerland). Dioleoyl- and dielaidoylphosphatidylcholines (DOPC and DEPC) were from Serva (Heidelberg, FRG). Spin-labeled maleimide, MSL, was from Syva (Palo Alto, CA) and is now available from Aldrich Chemical Co. (Milwaukee, WI). Sodium cholate was prepared from recrystallized cholic acid (Sigma, St. Louis, MO).

Enzyme Isolation. Cytochrome oxidase was isolated from bakers' yeast (United Yeasts, Morley, U.K.) as described by Eytan and Schatz (1975) and stored under liquid nitrogen in $10 \mathrm{mM}$ Tris, pH 7.5, buffer containing $1 \%$ Tween 80 . The heme content of the enzyme was $7-8 \mathrm{nmol} / \mathrm{mg}$ of protein, and the specific activity was between 1700 and $2800 \mathrm{~min}^{-1} / \mathrm{mg}$ of protein (assay methods are described below). PAGE electrophoresis in SDS revealed bands at 40,33, 25, 17, 15, and $9.5 \mathrm{kDa}$, as reported by Eytan and Schatz (1975), without higher molecular mass contaminants. There was variability between preparations in the content of the $25-\mathrm{kDa}$ subunit.

Spin-Labeling. Purified cytochrome oxidase at a concentration of $18 \mathrm{mg} / \mathrm{mL}$ was incubated for $15 \mathrm{~min}$ with $3 \mathrm{mg} / \mathrm{mL}$ maleimide spin-label in TKS buffer and $0.5 \%$ Tween 80 (total volume $1 \mathrm{~mL}$ ), at room temperature. Unreacted spin-label was removed by passage through a Sephadex G-25 column. The labeling level was determined to be ca. $2 \mathrm{~mol}$ of MSL/ 200-kDa protein, by quantitative ESR spectroscopy.

In order to obtain a rigid-limit ESR spectrum of labeled enzyme, $1 \mathrm{mg} / \mathrm{mL}$ reconstituted cytochrome oxidase was incubated at $0^{\circ} \mathrm{C}$ with $40 \mathrm{mM}$ glutaraldehyde for $2 \mathrm{~h}$. The

\footnotetext{
${ }^{1}$ Abbreviations: ESR, electron spin resonance; STESR, saturationtransfer electron spin resonance; $V_{2}^{\prime}$, second harmonic, absorption ESR spectrum detected $90^{\circ}$ out-of-phase with respect to the field modulation; $\mathrm{V}_{1}$, first harmonic, absorption ESR spectrum detected in-phase with respect to the field modulation; MSL, 4-maleimido-2,2,6,6-tetramethyl-1-piperidineoxyl; DMPC, 1,2-dimyristoyl-sn-glycero-3-phosphocholine; DOPC, 1,2-dioleoyl-sn-glycero-3-phosphocholine; DEPC, 1,2dielaidoyl-sn-glycero-3-phosphocholine; Tris, tris(hydroxymethyl)aminomethane; EDTA, ethylenediaminetetraacetic acid; TKS buffer, 10 $\mathrm{mM}$ Tris, $1.0 \mathrm{M} \mathrm{KCl}, 1 \mathrm{mM}$ EDTA, and $1 \%(\mathrm{w} / \mathrm{v})$ sucrose, $\mathrm{pH} 7.4$.
}

immobilized sample was collected by centrifugation and washed repeatedly prior to study.

Lipid Exchange. The endogenous lipid and detergent associated with purified and spin-labeled cytochrome oxidase were exchanged for synthetic lipids, DMPC, DOPC, and DEPC, according to the method described in Knowles et al. $(1979,1981)$. This procedure resulted in $\geq 98.5 \%$ efficiency of lipid exchange, as determined by gas-liquid chromatography [cf. Watts et al. (1978)]. After the final lipid exchange, the enzyme was resuspended in $10 \mathrm{mM}$ Tris, $1 \mathrm{M} \mathrm{KCl}, 1 \mathrm{mM}$ EDTA, and $1 \%(\mathrm{w} / \mathrm{v})$ sucrose, $\mathrm{pH} 7.4$, buffer (TKS buffer) containing $1.5 \%$ sodium cholate and centrifuged at $60000 \mathrm{~g}$ for $15 \mathrm{~min}$ to remove any aggregated protein. To check on homogeneity before the dialysis, a test aliquot of the supernatant was subjected to chromatography at $4^{\circ} \mathrm{C}$ on a Sepharose $4 \mathrm{~B}$ column, equilibrated with $1.5 \%$ cholate and a $0.2 \mathrm{mg} / \mathrm{mL}$ sample of the synthetic lipid in question. The column had previously been calibrated using thyroglobulin, ferritin, aldolase, blue dextran (void volume), and chromate (total volume) as markers. The solubilized cytochrome oxidase was found to elute as a single peak corresponding to an effective molecular mass of $380 \mathrm{kDa}$. Prior to detergent removal, the appropriate amount of lipid in $1.5 \%$ cholate was added to generate samples of varying lipid to protein ratio.

Reconstitution. Dialysis was the method used most frequently for detergent removal [cf. Racker (1972)]. The samples were dialyzed for $40 \mathrm{~h}$ at $15^{\circ} \mathrm{C}$ (unless otherwise stated) against three changes of a 1000-fold excess of TKS buffer containing Amberlite XAD-2 ion-exchange resin. For samples substituted with DOPC or DEPC, dialysis was performed under an atmosphere of oxygen-free nitrogen. Cholate removal was monitored by using $\left[{ }^{14} \mathrm{C}\right]$ cholate (Amersham, U.K.). After dialysis, the final cholate/lipid ratio was $0.015-0.018 \mathrm{~mol} / \mathrm{mol}$ for reconstituted cytochrome oxidase complexes, although lower ratios $(0.005 \mathrm{~mol} / \mathrm{mol})$ could be achieved under the same dialysis conditions for samples containing no protein.

The alternative method for detergent removal, used with some samples, was gel filtration on a Sephadex G-50 column (Brunner et al., 1976). The column (16-mm diameter $\times 250$ $\mathrm{mm}$ ) was pretreated with sonicated DMPC vesicles to minimize binding of the cytochrome oxidase-DMPC vesicles, and then equilibrated with TKS buffer. The solubilized enzyme (0.5-1.0 mL) was applied to the column and eluted at a flow rate of $0.3 \mathrm{~mL} / \mathrm{min}$ with TKS buffer. Chromatography at $25^{\circ} \mathrm{C}$, a temperature above the lipid-phase transition, produced vesicles of size $70-100 \mathrm{~nm}$, which was sufficiently large to ensure a homogeneous protein distribution with varying lipid/protein ratio [cf. Madden et al. (1984)]. Cholate removal was found to be as efficient by this method as by the dialysis procedure.

Characterization of Reconstituted Complexes. Enzymatic activity after reconstitution was routinely measured by cholate dilution assay in which the enzyme was first preincubated at $0{ }^{\circ} \mathrm{C}$ in TKS-0.5\% cholate, prior to 100 -fold dilution into the assay volume. Full activity was retained in the cytochrome oxidase-DMPC samples during lipid exchange and reconstitution by dialysis. Samples subjected to detergent removal by column chromatography at $25^{\circ} \mathrm{C}$ retained $70 \%$ of their activity on reconstitution. With the DOPC and DEPC complexes reconstituted by dialysis, the activity recovered was $1450-1950 \mathrm{~min}^{-1} / \mathrm{mg}$ of protein and $1450-1900 \mathrm{~min}^{-1} / \mathrm{mg}$ of protein, respectively.

The extent of protein aggregation after reconstitution was determined routinely by chromatography of a small aliquot 
of the reconstituted enzyme, solubilized in $1.5 \%$ cholate, on a calibrated column of Sepharose 4B, as described above. For DMPC-cytochrome oxidase complexes, most preparations eluted as a single peak at $390 \mathrm{kDa}$, and only these preparations were used. Reconstitution with the unsaturated lipids, DOPC and DEPC, sometimes produced preparations in which a significant fraction of the enzyme eluted at the void volume of the column. In the case of reconstitutions in DEPC, this aggregated material was a minor portion of the total: the DEPC-cytochrome oxidase samples were essentially nonaggregated before STESR study. However, for reconstitutions in DOPC, a considerable amount of the protein was always found to be aggregated: up to $100 \%$ of the material eluted with the void volume for the DOPC-cytochrome oxidase complexes.

The homogeneity of the reconstituted complexes was checked by density gradient centrifugation on $4-60 \%$ linear sucrose gradients $(78000 \mathrm{~g}, 12 \mathrm{~h})$. Most samples sedimented as a single band whose position in the gradient corresponded to the lipid/protein ratio. Occasionally, samples with high lipid/protein ratio ( $>1000: 1 \mathrm{~mol} / \mathrm{mol})$ sedimented as two bands; these samples were discarded.

Biochemical Assays. The protein concentration was measured by a modification of the Lowry method (Dulley \& Grieve, 1975). Phospholipid content was assayed according to Eibl and Lands (1969). Heme $a$ content was determined from the spectrum of reduced cytochrome oxidase, $\epsilon_{603}-\epsilon_{630}$ $=16.5 \mathrm{mM}^{-1} \mathrm{~cm}^{-1}$ (Eytan \& Schatz, 1975). Enzymatic activity was measured spectrophotometrically by following the oxidation of reduced cytochrome $c$ at $550 \mathrm{~nm}$ as described by Smith (1955). The assay medium contained $40 \mathrm{mM}$ phosphate buffer, $\mathrm{pH} 6.5$, and $30 \mu \mathrm{M}$ reduced cytochrome $c$ in a total volume of $1 \mathrm{~mL}$, and the assay temperature was $25^{\circ} \mathrm{C}$.

Electron Microscopy. Samples were applied to copper grids, equilibrated at the desired temperature, and then frozen rapidly in a slurry of Freon-22. Freeze-fracture, etching, platinum shadowing, and coating with carbon were carried out in a Balzers BAF 400D apparatus. The replicas were examined with either a Siemens 101 or a Phillips 200 electron microscope.

ESR Spectroscopy. Samples $1 \mathrm{~cm}$ long were prepared in 1-mm-diameter quartz capillaries by centrifugation in a bench centrifuge at $3000 \mathrm{rpm}$ for $1 \mathrm{~h}$ at $4^{\circ} \mathrm{C}$. The pellet was gently mixed to ensure uniform sample packing, and the sample was centered in the Varian TE102 cavity using a specially designed vernier holder. Saturation-transfer ESR spectra were recorded in the second harmonic, $90^{\circ}$ out-of-phase, absorption mode $\left(\mathrm{V}_{2}^{\prime}\right.$ display) at a modulation frequency of $50 \mathrm{kHz}$ and a modulation amplitude of $5 \mathrm{G} \mathrm{p}-\mathrm{p}$, using a Varian Century Line $9-\mathrm{GHz}$ spectrometer. The phase was set by the self-null method at subsaturating microwave power levels of $0.5 \mathrm{~mW}$ or less. The cavity filling factors were calculated, and the microwave power was adjusted to yield an average microwave field of $0.25 \mathrm{G}$ across the sample (Fajer \& Marsh, 1982). Temperature was controlled by thermostated nitrogen gas flow and measured by a fine-wire thermocouple placed close to the sample just within the microwave cavity.

Continuous wave power saturation experiments were performed to check the saturation characteristics of the sample. The amplitude of the low-field signal was recorded as a function of power, and the $P_{1 / 2}$ values corresponding to the level of half-saturation were determined from the linear dependence on the square root of the power.

Effective rotational correlation times were obtained by comparison with spectra of MSL-labeled hemoglobin tumbling

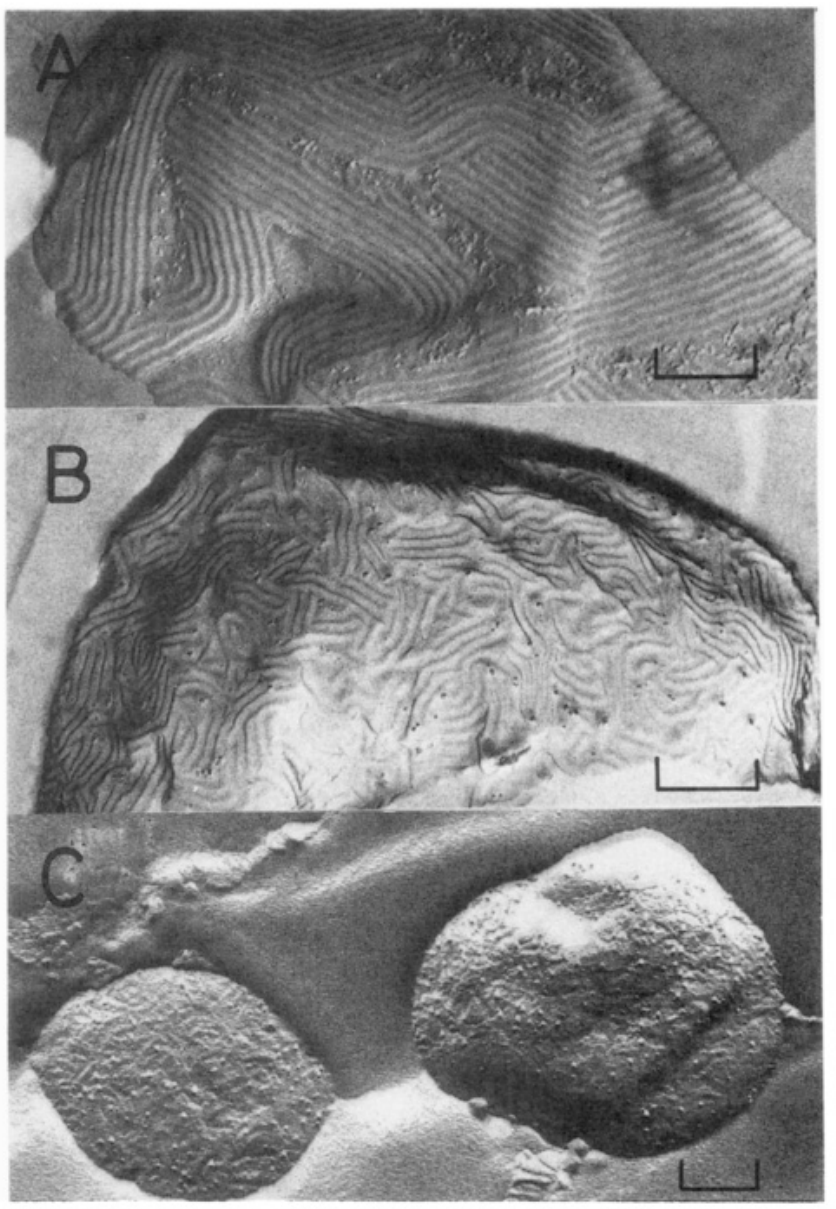

FIGURE 1: Freeze-fracture electron micrographs of cytochrome oxidase-DMPC complexes quenched from the following temperatures: (A) $0{ }^{\circ} \mathrm{C}$, lipid $/$ protein $=550 / 1 \mathrm{~mol} / \mathrm{mol}$; (B) $22^{\circ} \mathrm{C}$, lipid $/$ protein $=550 / 1 \mathrm{~mol} / \mathrm{mol} ;$ (C) $30^{\circ} \mathrm{C}$, lipid $/$ protein $=440 / 1 \mathrm{~mol} / \mathrm{mol}$. The bar represents $200 \mathrm{~nm}$ in each case.

isotropically in glycerol-water mixtures. The viscosities were determined by using Ubbelohde viscometers, and rotational correlation times were obtained from the Debye equation. The diagnostic line-height ratios introduced by Thomas et al. (1976) were used for the comparison. These calibration curves were presented elsewhere (Fajer \& Marsh, 1982). The small contaminating mobile peaks in the cytochrome oxidase STESR spectra were removed by subtraction using the STESR spectra of free MSL in $80 \mathrm{~mol} \%$ aqueous glycerol. In order to minimize the effects of any differences in the local nitroxide environment between cytochrome oxidase and hemoglobin, the line-height ratios for the two samples were normalized to those at the rigid limit. The rigid limit for cytochrome oxidase was obtained from a glutaraldehyde cross-linked sample at $1{ }^{\circ} \mathrm{C}$, and that for hemoglobin corresponded to the sample with a 3-ms rotational correlation time.

\section{RESULTS}

Electron Microscopy. Freeze-fracture electron micrographs of reconstituted complexes of cytochrome oxidase with dimyristoylphosphatidylcholine are given in Figure 1. The samples have been quenched from temperatures below (A), close to (B), and above (C) the gel-to-fluid-phase transition of DMPC. The micrographs display both the surface structures characteristic of the different lipid phases and the intramembranous particles characteristic of large integral membrane proteins [see, e.g., Kleeman and McConnell (1976)]. In Figure 1A, there is a very clear phase separation 


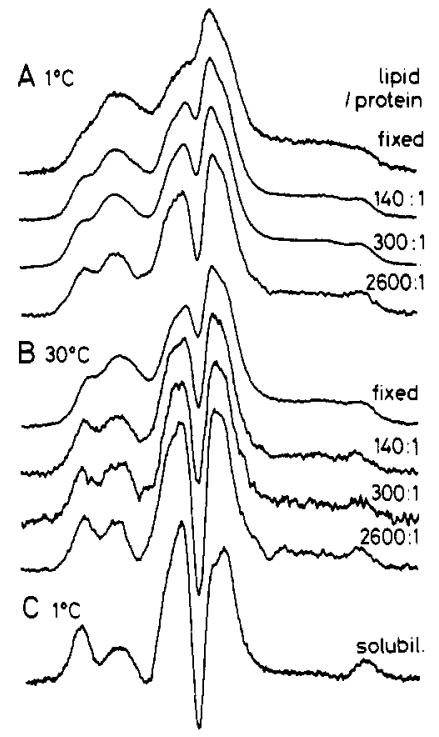

FIGURE 2: Second harmonic, $90^{\circ}$ out-of-phase absorption STESR spectra $\left(\mathrm{V}_{2}^{\prime}\right)$ of MSL-labeled cytochrome oxidase in DMPC complexes of the indicated lipid/protein mole ratios, and of a complex fixed with $40 \mathrm{mM}$ glutaraldehyde (fixed). (A) Spectra recorded at $1^{\circ} \mathrm{C}$; (B) spectra recorded at $30^{\circ} \mathrm{C}$; (C) spectrum of a sample in $1 \%$ Emulgen 913 (solubilized), recorded at $1^{\circ} \mathrm{C}$. Scan width $=100 \mathrm{G}$.

between the banded areas of pure gel-phase lipid and the particle-rich regions of segregated protein. Figure 1B represents an intermediate state. The gel phase has become less ordered, and the intramembranous particles are more uniformly distributed. In Figure 1C, the characteristic surface structures of the lipid gel phase are lost, and the intramembranous particles are distributed more or less randomly in the plane of the lipid bilayer. Quantitation of the number of particles per unit area in the fluid phase shows that these are underrepresented relative to the number of proteins calculated from the lipid/protein ratio. Both this and the size of the particles (ca. $75 \AA$ ) suggest that each particle corresponds to more than one protein molecule.

Saturation-Transfer ESR Spectra $\left(V_{2}{ }^{\prime}\right)$. Representative saturation-transfer ESR spectra of MSL-labeled cytochrome oxidase reconstituted with DMPC at different lipid/protein ratios are given in Figure 2. In the gel phase at $1^{\circ} \mathrm{C}$, the spectra display relatively little dependence on lipid/protein ratio and are rather similar to the spectrum of a sample in which the protein has been cross-linked by glutaraldehyde treatment (see Figure 2A). Quite large spectral changes are seen on going to the fluid phase at $30^{\circ} \mathrm{C}$ (except for the cross-linked sample), indicating an increase in rotational mobility of the protein. In the fluid phase, there is also a considerable dependence of the spectra on lipid/protein ratio (see Figure 2B). The spectrum of spin-labeled cytochrome oxidase in detergent (Figure 2C) is indicative of an even higher degree of rotational mobility than for the protein in fluid-phase lipid bilayers at high lipid/protein ratio, as is expected from the lower effective viscosity of the detergent solution.

The concentration and temperature dependence of the rotational mobility of the protein can be quantitated in terms of the diagnostic line-height ratios in the low-field $\left(L^{\prime \prime} / L\right)$, central $\left(C^{\prime} / C\right)$, and high-field $\left(H^{\prime \prime} / H\right)$ regions of the STESR spectrum, as defined by Thomas et al. (1976). The diagnostic line-height ratios are given in Figure 3 as a function of lipid/protein ratio, for temperatures both below and above the gel-to-fluid-phase transition. A marked, although rather different, dependence on protein concentration is seen in both fluid and gel phases. The dependence of the diagnostic lineheight ratios on temperature for samples both of low and of

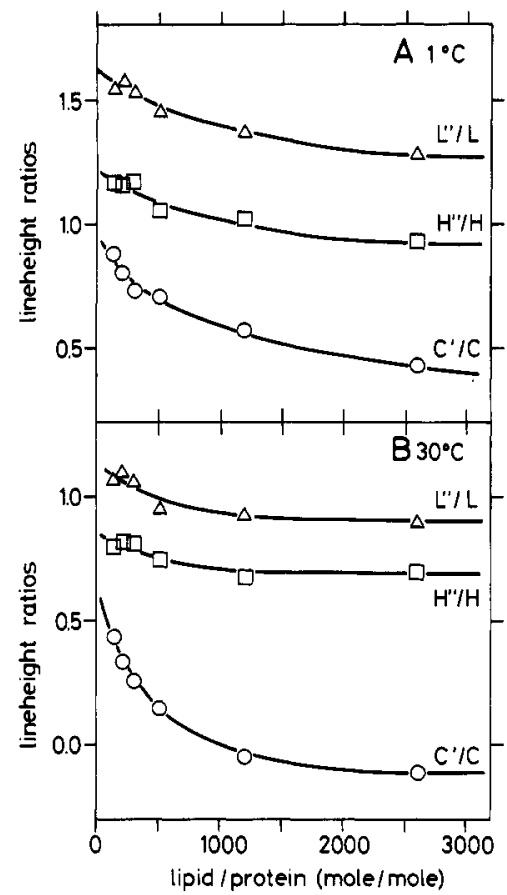

FIGURE 3: Diagnostic line-height ratios in the $\mathrm{V}_{2}^{\prime}$ STESR spectra of spin-labeled cytochrome oxidase in DMPC complexes, as a function of lipid/protein mole ratio. (A) Spectra recorded at $1{ }^{\circ} \mathrm{C}$; (B) spectra recorded at $30^{\circ} \mathrm{C}$. $(\Delta)$ Low-field ratio, $L^{\prime \prime} / L ;(O)$ central ratio, $C^{\prime} / C$; (ם) high-field ratio, $H^{\prime \prime} / H$.

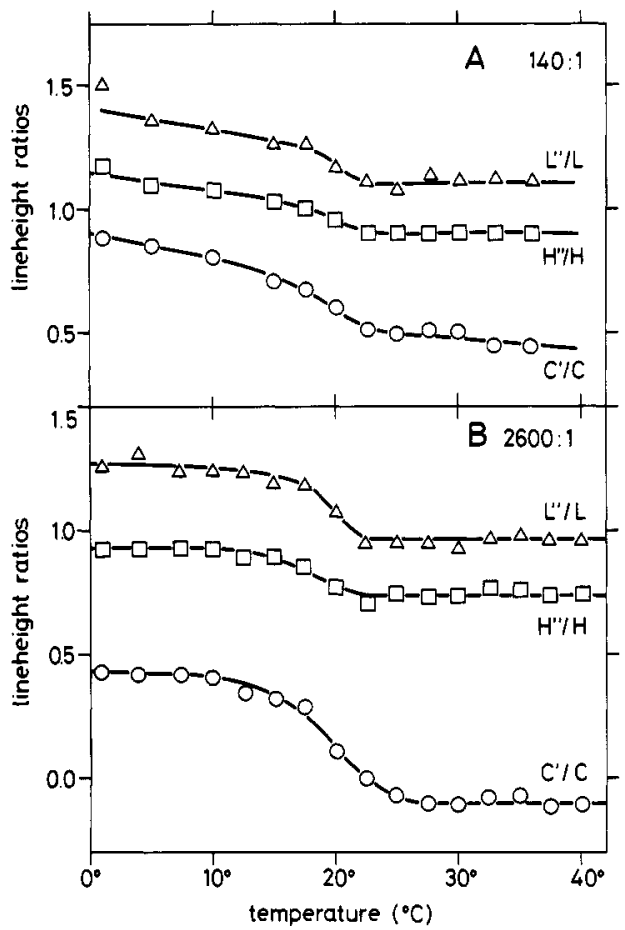

FIGURE 4: Diagnostic line-height ratios in the $\mathrm{V}_{2}^{\prime}$ STESR spectra of spin-labeled cytochrome oxidase in DMPC complexes as a function of temperature. (A) Complex of lipid/protein mole ratio 140/1; (B) complex of lipid/protein mole ratio $2600 / 1$. ( $\Delta$ ) Low-field ratio, $L^{\prime \prime} / L$; (O) central ratio, $C^{\prime} / C$; (ם) high-field ratio, $H^{\prime \prime} / H$.

high lipid/protein ratio is given in Figure 4. The effects of the cooperative lipid-phase transition at $20-22^{\circ} \mathrm{C}$ are very clearly seen, the larger change being observed at the higher lipid/protein ratio.

The STESR diagnostic line-height ratios in Figures 3 and 4 and Table I can be expressed in terms of effective rotational correlation times using calibrations for isotropically tumbling spin-labeled hemoglobin (Fajer \& Marsh, 1982). A prere- 
Table I: Diagnostic Line-Height Ratios, $L^{\prime \prime} / L, C^{\prime} / C$, and $H^{\prime \prime} / H$, in the Second Harmonic $90^{\circ}$ Out-of-Phase Absorption STESR Spectra $\left(\mathrm{V}_{2}{ }^{\prime}\right)$ of Maleimide-Spin-Labeled Cytochrome Oxidase in Lipid Complexes with DOPC, DEPC, and DMPC

\begin{tabular}{ccccc}
\hline $\begin{array}{c}\text { lipid/protein } \\
\text { ratio } \\
(\mathrm{mol} / \mathrm{mol})\end{array}$ & temp $\left({ }^{\circ} \mathrm{C}\right)^{a}$ & $L^{\prime \prime} / L$ & $C^{\prime} / C$ & $H^{\prime \prime} / H$ \\
\hline $\begin{array}{c}\text { DOPC } \\
430\end{array}$ & 1 & 1.30 & 0.78 & 0.95 \\
& 30 & 1.22 & 0.62 & 0.84 \\
& 10 & 1.38 & 0.81 & 1.03 \\
625 & 20 & 1.33 & 0.74 & 0.83 \\
& 1 & 1.21 & 0.75 & 0.90 \\
DEPC & 30 & 1.02 & 0.52 & 0.75 \\
$255^{b}$ & 1 & 1.41 & 0.94 & 1.29 \\
& 20 & 1.05 & 0.59 & 1.00 \\
$265^{c}$ & 33 & 0.96 & 0.38 & \\
& 1 & 1.52 & 0.96 & \\
DMPC & 20 & 1.00 & 0.61 & \\
205 & 33 & 0.95 & 0.36 & \\
$300^{d}$ & 30 & 1.10 & 0.34 & 0.82 \\
380 & 30 & 1.06 & 0.26 & 0.81 \\
511 & 30 & 0.93 & 0.37 & 0.82 \\
$600^{d}$ & 30 & 0.95 & 0.15 & 0.75 \\
& & 0.90 & 0.28 & 0.75 \\
\hline
\end{tabular}

- Temperatures arranged in chronological order in which data were collected. ${ }^{b} \mathrm{Complexes}$ formed by dialysis at $4{ }^{\circ} \mathrm{C}$. ${ }^{\circ}$ Complexes formed by dialysis at $16^{\circ} \mathrm{C}$. ${ }^{d}$ Complexes formed by gel chromatography on Sephadex G-50 at $25^{\circ} \mathrm{C}$.

Table II: Half-Saturation Powers, $P_{1 / 2}$, of Maleimide-Spin-Labeled Hemoglobin in Glycerol-Water $(58 \mathrm{~mol} \%$ ) and of Cytochrome Oxidase in DMPC Complexes of Different Lipid/Protein Ratios

\begin{tabular}{lcccc}
\hline \multicolumn{1}{c}{ sample } & $\begin{array}{c}\text { lipid/pro- } \\
\text { tein ratio } \\
\text { (mol/mol) }\end{array}$ & \multicolumn{2}{c}{$\boldsymbol{P}_{1 / 2}(\mathrm{~mW})$} \\
\hline hemoglobin & $1^{\circ} \mathrm{C}$ & $30^{\circ} \mathrm{C}$ \\
cytochrome oxidase-DMPC & 130 & 19 & $27^{\circ}$ \\
cytochrome oxidase-DMPC & 290 & 18 & 31 \\
cytochrome oxidase-DMPC & 1020 & 20 & 43 \\
cytochrome oxidase-DMPC & 2600 & 17 & 42 \\
cytochrome oxidase, glutaraldehyde fixed & & 21 & 15 \\
\hline${ }^{a}$ Value for $20^{\circ} \mathrm{C}$. & & & \\
\hline
\end{tabular}

quisite is that the changes in line-height ratios arise from saturation transfer induced by rotational motion, rather than from changes in the intrinsic saturation properties per se. To check this, continuous wave saturation measurements have been performed on the different samples in the different mobility states. The values of the power corresponding to $50 \%$ saturation, $P_{1 / 2}$, are given for the samples of different lipid/protein ratios, at temperatures above and below the gelto-fluid-phase transition, in Table II. The values do not vary greatly between the different samples at a given temperature and are very similar to those for the hemoglobin calibration system at both temperatures. This means that the intrinsic saturation parameters do not change very appreciably. Thus, the STESR diagnostic line-height ratios can be taken as reliable indicators of rotational mobility. The corresponding effective rotational correlation times, $\tau_{\mathrm{R}}\left(M_{\mathrm{I}}\right)$, deduced from the hemoglobin isotropic reference spectra are given in Table III.

A time-dependent aggregation was seen in the fluid phase. The dependence of the STESR diagnostic line-height ratios for the spin-labeled cytochrome oxidase on time of incubation at $30^{\circ} \mathrm{C}$ is given for complexes of two different lipid/protein ratios in Figure 5. The effects are greater at the higher protein concentration. A clear increase in the line-height ratios, corresponding to a decreased rotational mobility, takes place
Table III: Effective Rotational Correlation Times (in $\mu \mathrm{s}$ ) Derived from the Low-Field, Central, and High-Field Diagnostic Regions $\left[\tau_{R}(+1), \tau_{R}(0)\right.$, and $\tau_{R}(-1)$, Respectively] in the $V_{2}^{\prime}$ STESR Spectra of MSL-Labeled Cytochrome Oxidase in DMPC Complexes

\begin{tabular}{cccccccc}
\hline $\begin{array}{c}\text { lipid/pro- } \\
\text { tein ratio } \\
\text { (mol/mol) }\end{array}$ & \multicolumn{3}{c}{$1{ }^{\circ} \mathrm{C}$} & & \multicolumn{3}{c}{$30^{\circ} \mathrm{C}$} \\
\cline { 2 - 4 } \cline { 5 - 7 } \cline { 5 - 7 } & $\tau_{\mathrm{R}}(+1)$ & $\tau_{\mathrm{R}}(0)$ & $\tau_{\mathrm{R}}(-1)$ & & $\tau_{\mathrm{R}}(+\mathrm{I})$ & $\tau_{\mathrm{R}}(0)$ & $\tau_{\mathrm{R}}(-1)$ \\
\hline $140 / 1$ & 400 & 3300 & 210 & & 75 & 13 & 86 \\
$205 / 1$ & 500 & 1000 & 230 & & 82 & 10 & 90 \\
$300 / 1$ & 380 & 130 & 210 & & 72 & 7.5 & 88 \\
$515 / 1$ & 250 & 90 & 175 & & 50 & 5.8 & 75 \\
$1020 / 1$ & 180 & 28 & 160 & & 46 & 4.0 & 60 \\
$2600 / 1$ & 135 & 12.5 & 103 & & 42 & 3.3 & 65 \\
\hline
\end{tabular}

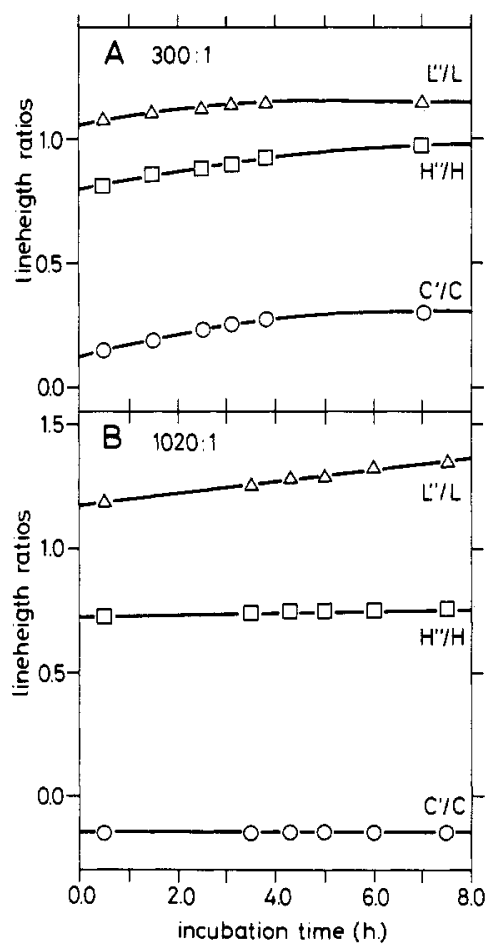

FIGURE 5: Dependence of the diagnostic STESR line-height ratios on time of incubation at $30^{\circ} \mathrm{C}$ for spin-labeled cytochrome oxidase in DMPC complexes. (A) Complex of lipid/protein mole ratio 300/1; (B) complex of lipid/protein mole ratio 1020/1. ( $\Delta$ ) Low-field ratio, $L^{\prime \prime} / L$; (O) central ratio, $C^{\prime} / C$; (ם) high-field ratio, $H^{\prime \prime} / H$.

over a time scale of approximately 4-8 $\mathrm{h}$.

In order to study the effects of chain unsaturation on the rotational mobility of the protein, spin-labeled cytochrome oxidase was reconstituted in DOPC. Column chromatography on Sepharose 4B in cholate (see Materials and Methods) revealed substantial aggregation of the protein in complexes with this cis-unsaturated phospholipid. This is reflected in the diagnostic line-height ratios from the STESR spectra of these preparations (see Table I). The line-height ratios are greater than those for DMPC complexes in the fluid phase, especially the central ratio $C^{\prime} / C$. This is in spite of the fact that DOPC is well above its phase transition for all temperatures studied.

The DOPC preparations differ from those with DMPC in that the reconstitution is, of necessity, performed with the lipid in the fluid phase (the transition temperature of DOPC is -22 ${ }^{\circ} \mathrm{C}$ ). Further reconstitutions were therefore performed, using the trans-unsaturated isomer DEPC which has a transition temperature of $+11.5^{\circ} \mathrm{C}$. The diagnostic line-height ratios of the STESR spectra from samples produced by reconstitution both above and below the phase transition temperature are given in Table I.

Enzyme Activity. The dependence of the enzyme activity on time has been studied in an attempt to correlate with the 


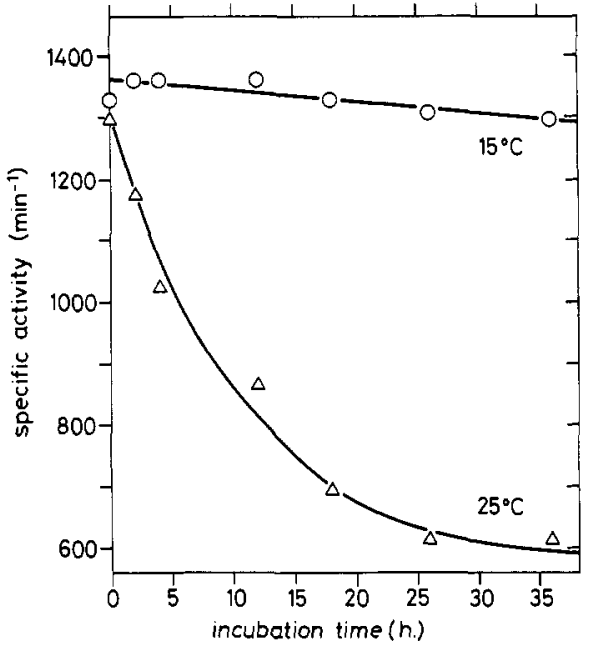

FIGURE 6: Dependence of cytochrome oxidase activity on time of incubation at $15^{\circ} \mathrm{C}(\mathrm{O})$ and at $25^{\circ} \mathrm{C}(\Delta)$, for a cytochrome oxidase-DMPC complex of lipid/protein mole ratio $440 / 1$.

results on the protein rotational mobility. The results for incubation at temperatures both above and below the lipidphase transition are given in Figure 6. The enzyme maintains its activity over a period of at least $36 \mathrm{~h}$ when incubated in the gel phase. A partial inactivation is observed, however, on prolonged incubation in the fluid phase. Approximately 50\% of the activity is lost after $36 \mathrm{~h}$.

The effect of the lipid-phase transition on the specific enzymatic activity has also been studied. Arrhenius plots of the temperature dependence of the enzymatic activity are given for complexes of cytochrome oxidase with DMPC and with DOPC in Figure 7. A clear break in the temperature dependence of the enzyme activity is seen at $22{ }^{\circ} \mathrm{C}$, corresponding to the phase transition temperature of DMPC, with activation energies of 28 and $51 \mathrm{~kJ} / \mathrm{mol}$ in the fluid and gel phases, respectively. For DOPC, on the other hand, which remains entirely in the fluid phase over the temperature range studied, no breaks in the linearity of the Arrhenius plot are observed. The temperature dependence in this case corresponds to a single activation energy of $44 \mathrm{~kJ} / \mathrm{mol}$. Similar data were obtained for samples of other lipid/protein ratios: from $190 / 1$ to $2400 / 1 \mathrm{~mol} / \mathrm{mol}$ of DMPC-cytochrome oxidase and from $70 / 1$ to $1050 / 1 \mathrm{~mol} / \mathrm{mol}$ of DOPC-cytochrome oxidase.

\section{Discussion}

The work presented in this paper addresses several different aspects of the rotational mobility and aggregation state of cytochrome oxidase and the effects of phosphatidylcholines of different chain compositions on these properties. The main method of investigation was the measurement of protein rotational diffusion, but important additional information was obtained from electron microscopy, activity measurements, and gel permeation chromatography. The various results are analyzed separately below, and finally a comparison is made with previous work, and the relevance to the mobility and interactions of cytochrome oxidase in the inner mitochondrial membrane is discussed.

Aggregation State in Phosphatidylcholines of Different Chain Composition. An important prerequisite for the present work was the production of reconstituted systems in which the cytochrome oxidase was not irreversibly aggregated [cf. Swanson et al. (1980)]. This was found possible for reconstitution with DMPC, using the procedure described under Materials and Methods. For the reconstitution with DOPC,

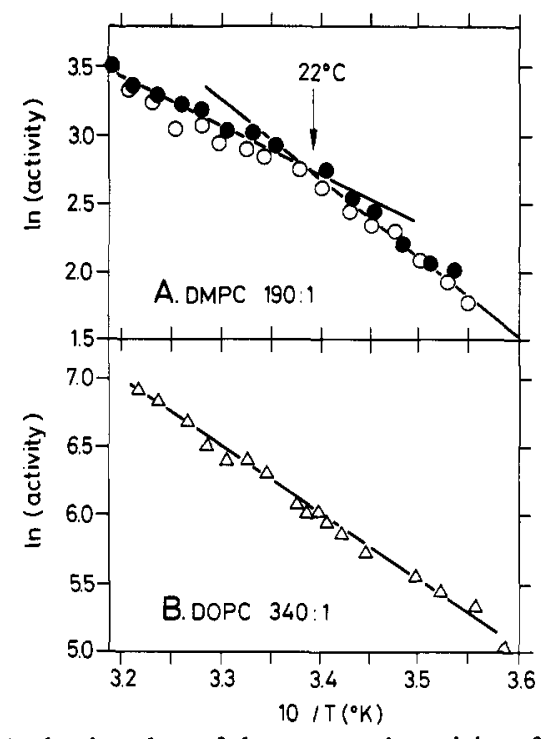

FIGURE 7: Arrhenius plots of the enzymatic activity of cytochrome oxidase-lipid complexes. Assays were performed directly on the reconstituted enzyme, not by dilution from cholate. (A) With DMPC at a lipid/protein mole ratio of 190/1 (O); (B) with DOPC at a lipid/protein mole ratio of $340 / 1(\Delta)$. Each point is the average of triplicate determinations; the closed symbols represent an independent duplicate run.

the protein underwent irreversible aggregation, as evidenced by subsequent chromatography in cholate on Sepharose 4B. On reconstitution with DEPC, a minor proportion of the material eluted with the void volume on Sepharose 4B chromatography in cholate. This is evidenced by the data from the STESR spectra of the reconstituted complexes with the different lipids, which are given in Table I. The diagnostic line-height ratios for the complexes with DOPC are all comparable to those obtained for the DMPC complexes in the gel phase, although the DOPC is in the fluid phase throughout the temperature range studied. In contrast, the line-height ratios for the DEPC complexes clearly reflect the gel-tofluid-phase transition. The values in the fluid and gel phases are comparable to those obtained for the DMPC complexes in these two phases. It is important to point out that although the enzyme is aggregated in DOPC it remains active. This is in accordance with the findings of Vik and Capaldi (1977) for the beef heart enzyme.

Two factors, one of which refers to the equilibrium state and the other of which is kinetic, that might affect the aggregation state of the enzyme in phosphatidylcholines of different chain composition are the hydrophobic span of the lipid bilayer and the fluidity of the membrane, respectively. Owicki et al. (1978) and Gruler and Sackmann (1977) have suggested that a mismatch between the hydrophobic span of the lipid bilayer and that of the integral protein introduces elastic distortions into the membrane which could drive protein aggregation. Aggregation could also be controlled kinetically by increased collision rates of the protein in media of lower viscosity. This would be especially important during reconstitution in which the protein concentrations are high and only DOPC is in the fluid phase. In the latter case, an irreversible aggregation may be induced during reconstitution. It seems possible that, generally, both factors will be operative in creating the different aggregation states of cytochrome oxidase when reconstituted in phosphatidylcholines of different chain lengths and different degrees and types of unsaturation.

Temperature Dependence of the Activity. The Arrhenius plot for the activity of the DMPC complex exhibits a clear break at the phase transition temperature of $22^{\circ} \mathrm{C}$. The 
difference in activation energies between the two phases (23 $\mathrm{kJ} / \mathrm{mol}$ ) is 4 times larger than the upper limit for which a continuously curving, rather than a biphasic linear, Arrhenius temperature dependence can be fitted (Silvius \& McElhaney, 1981). The break in gradient without an abrupt discontinuity in the activity is consistent with at least two of the mechanisms put forward by Silvius and McElhaney (1981). These are either a temperature-dependent conformational change in the enzyme (class III mechanism) or a preferential partitioning of the enzyme between the two lipid phases [class IV mechanism; see Thilo et al. (1977)]. The fact that the Arrhenius plot for the complex with DOPC is completely linear over the range studied indicates that, if the discontinuity at $22^{\circ} \mathrm{C}$ for the DMPC complex is due to a conformational change in the protein, this is not spontaneous but must be driven by the lipid-phase transition. These results for the yeast enzyme are different from those obtained by Yoshida et al. (1969) with the beef heart enzyme, for which a break in the Arrhenius plot was found in reconstitutions with DOPC. The segregation of the protein observed in the electron micrograph of the preparation in the gel phase of DMPC (Figure 1A) suggests that the partitioning of the protein may well be in favor of the fluid phase. In view of the different states of aggregation and mobility, it also seems likely that the conformation of the enzyme may be different in the two phases. Possibly both mechanisms contribute to the Arrhenius activity behavior of the enzyme reconstituted in DMPC.

Rotational Diffusion and Oligomer State. The dependence of the rotational diffusion coefficient, $D_{\mathrm{R}_{\mathrm{p}}}$, on protein size can be predicted from hydrodynamic theory [cf. Perrin (1934) and Saffmann and Delbrueck (1975)]. The frictional coefficient can be derived from the torque experienced by the rotating protein, assuming stick boundary conditions. For a cylindrical protein of elliptical cross section with semiaxes $a$ and $b$, the following expression for the diffusion coefficient is then obtained from the Stokes-Einstein relation:

$$
D_{\mathrm{R}_{f}}=k T /\left[2 \pi \eta h\left(a^{2}+b^{2}\right)\right]
$$

where $h \approx 45 \AA$ is the height of the membrane-spanning region of the cylinder, $\eta$ is the effective viscosity within the membrane, $k$ is Boltzmann's constant, and $T$ is the absolute temperature. Assuming values of $a=35 \AA$ and $b=15 \AA$ for monomeric cytochrome oxidase from electron microscopy and diffraction measurements (Deatheridge et al., 1982) yields values of $\tau_{R_{\|}}$ $=5-9 \mu$ s for realistic values of the membrane viscosity $[\eta=$ 2-5 P; cf. Cherry and Godfrey (1981)]. The cross-sectional dimensions of the cytochrome oxidase dimer found in twodimensional cholate-derived crystals are $a \approx 50 \AA$ and $b \approx$ $27 \AA$ (Deatheridge et al., 1982), giving values of $\tau_{R_{1}}=12-20$ $\mu \mathrm{s}$. By comparison, an end-to-end dimer of monomers would have a predicted correlation time in the range $\tau_{R_{\|}}=19-32$ $\mu \mathrm{s}$.

The values for the effective rotational correlation times, $\tau_{\mathrm{R}}\left(M_{\mathrm{I}}\right)$, deduced from calibration of the STESR line-height ratios using the hemoglobin isotropic model system, can be related to the true values for anisotropic rotation. Robinson and Dalton (1980) have performed theoretical line-shape simulations of first harmonic dispersion mode STESR spectra for nitroxide spin-labels undergoing anisotropic rotational diffusion. For highly anisotropic rotation $\left(D_{\mathrm{R}_{\mathrm{H}}} \gg D_{\mathrm{R}_{\perp}}\right)$ in the correlation time range relevant for membrane proteins, it was found that

$$
\tau_{\mathrm{R}}( \pm 1)=1 /\left\{3\left[D_{\mathrm{R}_{\sharp}} \sin ^{2} \theta+D_{\mathrm{R}_{\perp}}\left(1+\cos ^{2} \theta\right)\right]\right\}
$$

where $D_{\mathrm{R}_{\perp}}$ is the element of the diffusion tensor corresponding to rotations about an axis perpendicular to the principal axis of rotation and $\theta$ is the angle between the nitroxide $z$ axis and the principal rotation axis. Hence, neglecting $D_{\mathrm{R}_{\perp}}$, the true correlation time for rotation about the membrane normal, defined by $\tau_{R_{f}}=1 / 6 D_{R_{l}}$, is given by

$$
\tau_{R_{\|}}=1 / 2 \tau_{R}( \pm 1) \sin ^{2} \theta
$$

Therefore, the maximum value of $\tau_{R_{1}}$ is $\approx 25 \mu$ s for high lipid/protein ratios in the fluid phase (see Table III), corresponding to the spin-label orientation $\theta=90^{\circ}$. It thus appears that the cytochrome oxidase molecule is either a monomer or a dimer, but not a higher oligomer, in the reconstituted system. Since a closely associated dimer is found in the two-dimensional crystals and can be inferred from the chromatography of the DMPC-substituted enzyme in cholate (see Materials and Methods), it seems likely that this may be preserved in the reconstituted system.

For the STESR spectra to be consistent with a monomer would require that $\theta \approx 27-37^{\circ}$, and for a dimer that $\theta \approx$ $44-64^{\circ}$. However, these angles probably must be considered as average values because more than one site on the protein has been labeled. This also makes it unlikely that all labels would have the unique $\theta=90^{\circ}$ orientation, giving rise to the maximum value of $\tau_{R_{1}}$. It should be noted that the fact that the effective correlation times deduced from the central line-height ratios are shorter than those deduced from the outer line-height ratios positively indicates a highly anisotropic rotation, with the nitroxide $z$ axis being inclined toward the rotation axis (Marsh, 1980; Robinson \& Dalton, 1980). The central line-height ratio, however, is too sensitively dependent on the exact values of the nitroxide tensor elements to be useful in determining the true correlation time (Robinson \& Dalton, 1980).

Dependence of Rotational Diffusion on Protein Concentration. The effect of random protein-protein contacts on the rotational diffusion rates can be depicted by a simple model, in which the observed diffusion coefficient, $\left\langle D_{\mathrm{R}_{1}}\right\rangle$, is expressed as a statistical average of that for the freely rotating species, which does not experience any influence from other proteins $\left(D_{\mathrm{R}, \mathrm{f}}\right)$, and that for highly hindered species which has other proteins immediately adjacent $\left(D_{\mathrm{R}, \mathrm{h}}\right)$ :

$$
\left\langle D_{\mathrm{R}_{\mathrm{h}}}\right\rangle=D_{\mathrm{R}, \mathrm{f}} P+D_{\mathrm{R}, \mathrm{h}}(1-P)
$$

where $P$ denotes the probability for the freely rotating species. The condition for the validity of eq 4 is that the lifetime of the protein-protein contacts should be shorter than the rotation period. Assuming a value of $10^{-9} \mathrm{~cm}^{2} \mathrm{~s}^{-1}$ for the translational diffusion coefficient of the protein, the time required for a root mean square displacement equal to the diameter of a lipid molecule $(8 \AA)$ is approximately $1.6 \mu \mathrm{s}$. This can be taken to be the lifetime of the protein-protein complex, and is considerably less than the rotational correlation time of the protein, hence demonstrating the applicability of the model. An expression for $P$ can be obtained by using the lattice model of Hoffman et al. (1981), which was developed for calculating the frequency of integral protein contacts with lipid molecules. Each lipid molecule is assumed to occupy one lattice point and each protein molecule to occupy $R$ lattice points. $P$ is then the probability that all $N$ lattice points at the protein perimeter are occupied by lipid molecules:

$$
P=[1-R /(\mathrm{LP}+R)]^{N}
$$

where LP is the lipid/protein mole ratio. It should be noted that the value of $N$ is dependent on the degree of oligomerization, but the ratio $R /(\mathrm{LP}+R)$ in eq 5 is insensitive to the 


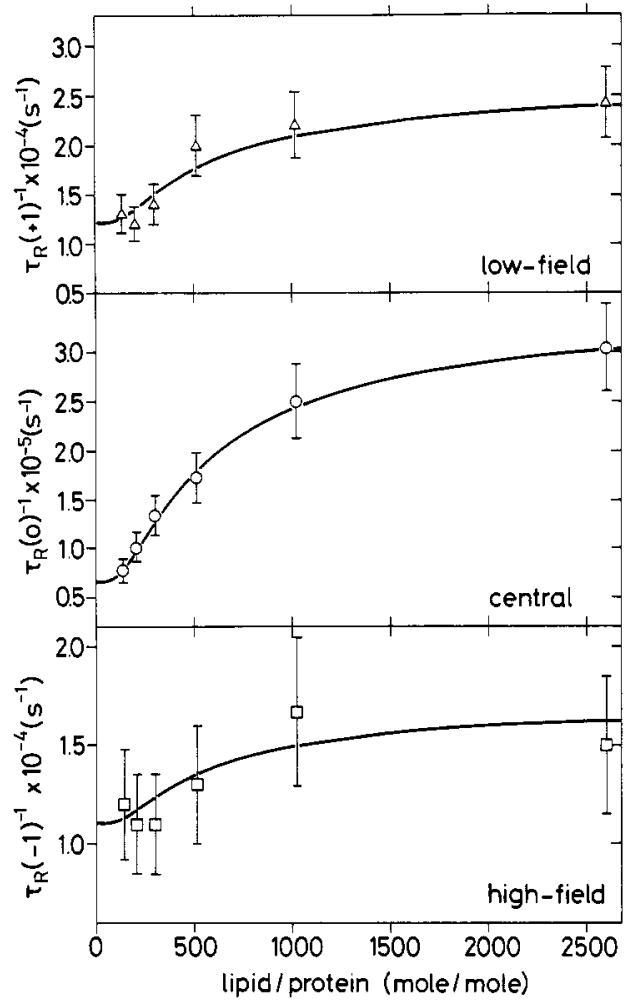

FIGURE 8: Dependence of the rotational relaxation rates, $\tau_{R}\left(M_{1}\right)^{-1}$, on lipid/protein mole ratio for cytochrome oxidase in DMPC complexes at $30^{\circ} \mathrm{C}$. Effective rotational correlation times are deduced from the line-height ratios in the diagnostic regions: (A) low-field, $\tau_{R}(+1)$; (B) central, $\tau_{R}(0)$; (C) high-field, $\tau_{R}(-1)$. Solid lines are theoretical calculations using the random collision model of eq 4 and 5 , with $N=18$ and $R=27$. For $\tau_{\mathrm{R}}(0)$, this represents a nonlinear least-squares fit with constant $R$.

degree of oligomerization, and therefore the value of $R$ appropriate to the monomer may be taken.

$D_{\mathrm{R}, \mathrm{h}}$ can be estimated from the mobility in samples of low lipid/protein ratio: $\mathrm{LP} \approx R+N$, or slightly higher to ensure Brownian diffusion and a homogeneous distribution of protein. $D_{\mathrm{R}, f}$ can be obtained by extrapolation to infinite lipid/protein ratio. Fits of the effective protein rotational rates, $\tau_{\mathrm{R}}\left(M_{\mathrm{I}}\right)^{-1}$, which are proportional to the rotational diffusion coefficient (cf. eq 2, above), have been made to the functional form of eq 4 and 5, and are given in Figure 8. The lipid/protein ratio dependence of $\tau_{R}(0)^{-1}$ is very well described by the nonlinear least-squares fit to this model, using $N$ as the parameter to be optimized. The value of $R=27$, corresponding to the cytochrome oxidase monomer (Deatheridge et al., 1982), was held constant during this fit. Because of the inherently greater experimental scatter, the parameters $N=18$ and $R=27$ were held constant at the values obtained from the $\tau_{R}(0)^{-1}$ fit when fitting the lipid/protein ratio dependence of $\tau_{R}( \pm 1)^{-1}$. These latter fits lie well within the experimental uncertainty, although the precision of the data is lower than that for $\tau_{\mathrm{R}}(0)^{-1}$. The value of $N=18$ lipid boundary sites on one side of the bilayer corresponds well with the dimensions of the low-resolution structure of the cytochrome oxidase dimer (Deatheridge et al., 1982; $\mathrm{cf}$. previous section). The effective number of boundary lipids per dimer, $2 N=36$, is somewhat less than the value of 45 per $160-\mathrm{kDa}$ protein found by lipid spin-label ESR measurements (Knowles et al., 1979). This presumably reflects the invaginated nature of the intramembranous surface of the protein [cf. Marsh (1985)], which is effectively smoothed when considering the protein-protein contacts. It will be noted that eq 5 , or similar equivalents, is also capable of describing the dependence of the number of lipid boundary sites on lipid/ protein ratio in cytochrome oxidase-DMPC complexes (Marsh et al., 1982; Hoffman et al., 1981).

Thus, it appears that the effects of lipid/protein ratio on the rotational mobility can be reasonably described in terms of random protein collisions occurring with increasing protein density. The effective lipid viscosity is also expected to increase with increasing protein concentration, and this has been suggested to be one of the reasons for the decreased mobility (Cherry \& Godfrey, 1981). An estimate of this effect can be made from the dependence of the viscosity on the volume fraction of solute, $\phi_{2}: \eta=\eta_{0}\left(1+\nu \phi_{2}\right)$, where $\eta_{0}$ is the viscosity of the pure solvent and $\nu$ is the shape-dependent Simha coefficient [see, e.g., Cantor and Schimmel (1980)]; hence

$$
\eta=\eta_{0}[1+\nu R /(\mathbf{L P}+R)]
$$

The diffusion coefficient is inversely related to the membrane viscosity (see eq 1), and numerical calculation for reasonable values of $\nu(\leq 5)$ indicates that eq 6 is insufficient to account for the whole of the lipid/protein ratio dependence given in Figure 8.

An alternative explanation for the decrease of the diffusion rates with protein concentration is that a heterogeneous population of rotating species, with varying proportions of higher oligomers, is produced. The statistical distribution or the equilibrium between the different species could be dependent on lipid/protein ratio. The observed saturation-transfer spectra would then be a superposition of the spectra with different mobilities. These overlapping spectra would not be resolved by this technique. Taking the static equivalent of the model with coexisting free (f) and hindered (h) rotating species, linear additivity of the spectral line heights leads to the expression for the lipid/protein ratio dependence of the diagnostic lineheight ratios:

$$
L^{\prime \prime} / L=\frac{P\left(L_{\mathrm{f}}^{\prime \prime} / L_{\mathrm{f}}\right)+(1-P)\left(L_{\mathrm{h}}{ }^{\prime \prime} / L_{\mathrm{h}}\right)\left(L_{\mathrm{h}} / L_{\mathrm{f}}\right)}{P+(1-P)\left(L_{\mathrm{h}} / L_{\mathrm{f}}\right)}
$$

where $L_{\mathrm{f}}^{\prime \prime} / L_{\mathrm{f}}$ and $L_{\mathrm{h}}{ }^{\prime \prime} / L_{\mathrm{h}}$ are the line-height ratios of the freely rotating and hindered species, respectively, and $P$ is given by eq 5. The ratio of the line heights of the two species at the stationary point, $L_{\mathrm{h}} / L_{\mathrm{f}}$, is also dependent on the rotational mobility [cf. Horvăth and Marsh (1983)] and must be greater than 1 , since $L_{h}$ corresponds to lower mobility. Simulation of the lipid/protein ratio dependence of the line-height ratios using eq 5 and 7 requires values of $L_{\mathrm{h}} / L_{\mathrm{f}}$ less than 1 , and therefore this model is inapplicable.

Comparison with Other Measurements and Functional Implications. Previous measurements of the rotational mobility of cytochrome oxidase using STESR have yielded effective rotational correlation times, $\tau_{\mathrm{R}}( \pm 1)$, of approximately $40 \mu \mathrm{s}$ for nonaggregated reconstituted preparations in asolectin, egg phosphatidylcholine, and mitochondrial lipids (Swanson et al., 1980) and $34 \mu$ s for a preparation in asolectin (Ariano \& Azzi, 1980). These values are similar to those obtained in the fluid phase, at high lipid/protein ratios, for the present DMPC-substituted preparations. Experiments using flash photolysis on cytochrome oxidase reconstituted in phosphatidylethanolamine-phosphatidylcholine-cardiolipin vesicles have yielded rather longer rotational relaxation times, which correspond to rotational correlation times, $\tau_{\mathrm{R}_{\mathrm{l}}}$, of approximately $80 \mu \mathrm{s}$ (Kawato et al., 1981). These values are more comparable to the values obtained for DOPC-substituted preparations in the present study (cf. Table I). In the flash photolysis work, a rotationally immobile population was observed at low lipid/protein ratios and was attributed to a nonspecific aggregation. The lipid/protein ratio dependence 
of the effective rotational correlation times in the DMPC recombinants in the fluid phase from the present work is better described by a transient collisional model (eq 4 and 5 and Figure 8). However, the time dependence of the STESR line-height ratios in Figure 5 indicate a slow irreversible aggregation in the fluid phase, which is dependent on the lipid/protein ratio.

Evidence has been presented that mitochondrial electron transport is based on independent diffusion of membrane components, being effected by random collision between them (Hackenbrock et al., 1986). With respect to cytochrome oxidase, this view is supported by rotational diffusion measurements which found no specific decrease in the rotational mobility of cytochrome oxidase in the presence of the cytochrome $b-c_{1}$ complex (Kawato et al., 1981). The analysis of the lipid/protein ratio dependence of the rotational diffusion of cytochrome oxidase in fluid-phase bilayers given above also favors a random collisional model for the protein-protein interactions (Figure 8). Furthermore, the estimates of the lifetime of the collisional complexes (ca. $1.6 \mu \mathrm{s}$ ) suggest that there is no large-scale reorientation within the lifetime of the complex and that multiple collisions are probably required to achieve the correct orientation for electron transfer. This seems to be consistent with analyses of the collisional efficiency of the electron-transport kinetics (Hackenbrock et al., 1986).

The measured rotational diffusion coefficients, $D_{\mathbf{R}_{\|}}$, may be used to predict the local translational diffusion coefficient, $D_{\mathrm{T}}$, of cytochrome oxidase, using the hydrodynamic model of Saffman and Delbrück (1975). Expressing the effective membrane viscosity in terms of the rotational diffusion coefficient, the relation is obtained (Peters \& Cherry, 1982):

$$
D_{\mathrm{T}}=\left\{\ln \left(k T / 4 \pi \eta_{\mathrm{w}} D_{\mathrm{R}_{\|}} a^{3}\right)-0.5772\right\} D_{\mathrm{R}_{\|}} a^{2}
$$

where $\eta_{w}(=1 \mathrm{cP})$ is the viscosity of the aqueous phase and $a$ is the radius of the equivalent circular protein cylinder [taken as $(a b)^{1 / 2}$ from the semiaxes of the elliptical cross section of the protein (Deatheridge et al. (1982)]. Taking a value of $D_{\mathrm{R}_{\|}}$ $=3.9 \times 10^{3} \mathrm{~s}^{-1}$, corresponding to the DMPC complex of lowest lipid/protein ratio (which is similar to that in the inner mitochondrial membrane), the local translational diffusion coefficient is predicted to be $3.6 \times 10^{-9} \mathrm{~cm}^{2} \mathrm{~s}^{-1}$ for the cytochrome oxidase dimer $\left(1.7 \times 10^{-9} \mathrm{~cm}^{2} \mathrm{~s}^{-1}\right.$, assuming a monomer) at $30^{\circ} \mathrm{C}$. If the aqueous viscosity in mitochondria is higher than this, then the predicted translational diffusion coefficient would be correspondingly lower. The long-range lateral diffusion coefficient of cytochrome oxidase in the mitochondrial inner membrane, measured by photobleaching techniques, has been found to be considerably lower than this. Values of $3.6 \times 10^{-10} \mathrm{~cm}^{2} \mathrm{~s}^{-1}$ (Gupte et al., 1984) and $1.5 \times$ $10^{-10} \mathrm{~cm}^{2} \mathrm{~s}^{-1}$ (Hochman et al., 1985) have been reported. The difference between these values and the predictions of the local diffusion coefficient is too large to be accounted for by differences in either the aqueous or the membrane viscosity and implies that the long-range protein diffusion in the inner mitochondrial membrane is restricted relative to the shortrange diffusion. Correspondingly, short-range diffusion will be more efficient than long-range diffusion in establishing contact between components of the mitochondrial respiratory chain, if the necessary components are present in the same local region.

\section{ACKNOWLEDGMENTS}

We thank Prof. G. Schatz of the Biocentre, University of Basel, for helpful advice and for providing samples of cyto- chrome oxidase for comparison with our own preparations.

Registry No. DMPC, 13699-48-4; DOPC, 10015-85-7; DEPC, 52088-89-8; cytochrome oxidase, 9001-16-5.

\section{REFERENCES}

Ariano, H. A., \& Azzi, A. (1980) Biochem. Biophys. Res. Commun. 93, 478-485.

Brunner, J., Scrabal, P., \& Hauser, H. (1976) Biochim. Biophys. Acta 455, 322-331.

Cantor, C. R., \& Schimmel, P. R. (1980) Biophysical Chemistry, Part II, W. H. Freeman, San Francisco.

Cevc, G., \& Marsh, D. (1987) Phospholipid Bilayers. Physical Principles and Models, 443 pp, Wiley-Interscience, New York.

Cherry, R. J., \& Godfrey, R. E. (1981) Biophys. J. 36, 257-276.

Deatheridge, J. F., Henderson, R., \& Capaldi, R. A. (1982) J. Mol. Biol. 158, 501-514.

Dulley, J. R., \& Grieve, P. A. (1975) Anal. Biochem. 64, 136. Eibl, H., \& Lands, W. E. M. (1969) Anal. Biochem. 30, 51-57.

Esmann, M., Horvâth, L. 1., \& Marsh, D. (1987) Biochemistry 26, 8675-8683.

Eytan, G. D., \& Schatz, G. (1975) J. Biol. Chem. 250, 767-774.

Fajer, P., \& Marsh, D. (1982) J. Magn. Reson. 49, 212-224.

Gruler, H., \& Sackmann, E. (1977) Croat. Chem. Acta 49, 379-388.

Gupte, S., Wu, E.-S., Höchli, L., Höchli, M., Jacobson, K., Sowers, A., \& Hackenbrock, C. R. (1984) Proc. Natl. Acad. Sci. U.S.A. 81, 2606-2610.

Hackenbrock, C. R., Chazotte, B., \& Gupte, S. S. (1986) J. Bioenerg. Biomembr. 18, 331-368.

Hemminga, M., de Jager, P. A., Marsh, D., \& Fajer, P. (1984) J. Magn. Reson. 49, 160-163.

Hochman, J., Ferguson-Miller, S., \& Schindler, M. (1985) Biochemistry 24, 2509-2516.

Hoffman, W., Pink, D. A., Restall, C., \& Chapman, D. (1981) Eur. J. Biochem. 114, 585-589.

Horvāth, L. I., \& Marsh, D. (1983) J. Magn. Reson. 54, 363-373.

Kawato, S., Sigel, E., Carafoli, E., \& Cherry, R. J. (1980) J. Biol. Chem. 255, 5508-5510.

Kawato, S., Sigel, E., Carafoli, E., \& Cherry, R. J. (1981) J. Biol. Chem. 256, 7518-7527.

Kawato, S., Lehner, C., Müller, M., \& Cherry, R. J. (1982) J. Biol. Chem. 257, 6470-6476.

Kleeman, W., \& McConnell, H. M. (1976) Biochim. Biophys. Acta 419, 206-222.

Knowles, P. F., Watts, A., \& Marsh, D. (1979) Biochemistry 18, 4480-4487.

Knowles, P. F., Watts, A., \& Marsh, D. (1981) Biochemistry 20, 5888-5894.

Madden, T. D., Hope, M. J., \& Cullis, P. R. (1984) Biochemistry 23, 1413-1418.

Marsh, D. (1980) Biochemistry 19, 1632-1637.

Marsh, D. (1985) in Progress in Protein-Lipid Interactions (Watts, A., \& De Pont, J. J. H. H. M., Eds.) Vol. 1, pp 143-172, Elsevier, Amsterdam.

Marsh, D., Watts, A., Pates, R. D., Uhl, R., Knowles, P. F., \& Esmann, M. (1982) Biophys. J. 37, 265-274.

Owicki, J. C., Springate, M. W., \& McConnell, H. M. (1978) Proc. Natl. Acad. Sci. U.S.A. 75, 1616-1625.

Perrin, F. (1934) J. Phys. Radium 5, 497-511.

Peters, R., \& Cherry, R. J. (1982) Proc. Natl. Acad. Sci. U.S.A. 79, 4317-4321. 
Racker, E. (1972) J. Membr. Biol. 10, 221-235.

Robinson, B. H., \& Dalton, L. R. (1980) J. Chem. Phys. 72, 1312-1324.

Saffman, P. G., \& Delbrück, M. (1975) Proc. Natl. Acad. Sci. U.S.A. 72, 3111-3113.

Silvius, J. R., \& McElhaney, R. N. (1981) J. Theor. Biol. 88, 135-152.

Smith, L. (1955) Methods Biochem. Anal. 2, 427-434.

Swanson, M. S., Quintanilha, A. T., \& Thomas, D. D. (1980)

J. Biol. Chem. 255, 7494-7502.
Thilo, L., Träuble, H., \& Overath, P. (1977) Biochemistry 16, 1283-1289.

Thomas, D. D., Dalton, L. R., \& Hyde, J. S. (1976) J. Chem. Phys. 65, 3006-3024.

Vik, S. B., \& Capaldi, R. A. (1977) Biochemistry 16, 5755-5759.

Watts, A., Marsh, D., \& Knowles, P. F. (1978) Biochem. Biophys. Res. Commun. 81, 403-409.

Yoshida, S., Orii, Y., Kawato, S., \& Ikegami, A. (1979) J. Biochem. 86, 1443-1450.

\title{
Polymorphic Phase Behavior of Lysopalmitoylphosphatidylcholine in Poly(ethylene glycol)-Water Mixtures ${ }^{\dagger}$
}

\author{
Martin D. King ${ }^{\ddagger}$ and Derek Marsh* \\ Max-Planck-Institut für biophysikalische Chemie, Abteilung Spektroskopie, D-3400 Göttingen, Federal Republic of Germany \\ Received November 28, 1988; Revised Manuscript Received March 17, 1989
}

\begin{abstract}
The polymorphic phase behavior of 1-palmitoyl-2-lyso-sn-glycero-3-phosphocholine dispersions in excess water has been studied as a function of temperature and poly(ethylene glycol) (PEG) concentration, using proton dipolar-decoupled ${ }^{31} \mathrm{P}$ NMR spectroscopy and turbidity measurements. The phase behavior was found to depend on both lipid concentration and PEG concentration, and most of the NMR experiments were conducted at a lipid concentration of $15 \mathrm{mg} / \mathrm{mL}$. At low PEG concentrations (0-12 wt \%), a thermotropic transition occurs at $3-5^{\circ} \mathrm{C}$ with increasing temperature, from an interdigitated lamellar gel $\left(\mathrm{L}_{\beta}{ }^{\mathrm{i}}\right)$ phase to a normal micellar phase. At intermediate PEG concentrations $(12-20 \mathrm{wt} \%)$, thermotropic transitions take place with increasing temperature, first from the lamellar gel phase to a fluid cubic $\left(Q_{\alpha}\right)$ phase and then at higher temperatures from the cubic phase to the micellar phase. At intermediate PEG concentrations above the former range (20-30 wt \%), thermotropic transitions take place with increasing temperature, first from the lamellar gel phase to the cubic phase, then from the cubic phase to a normal hexagonal $\left(\mathrm{H}_{\mathrm{I}}\right)$ phase, and finally from the hexagonal phase to the micellar phase. At high PEG concentrations $(>30 \mathrm{wt} \%)$, a thermotropic transition takes place with increasing temperature from the lamellar gel phase directly to the fluid hexagonal phase. At these high PEG concentrations, the micellar phase is not attained within the accessible temperature range $\left(\leq 90^{\circ} \mathrm{C}\right)$. The kinetics of some of the phase changes are slow with half-times of the order of $15 \mathrm{~min}$, and considerable hysteresis, with coexisting phases, is observed on the downward temperature scans. The turbidity measurements indicate considerable changes in optical density in single phase regions, presumably corresponding to changes in aggregate size. Discontinuities in the temperature dependence of the optical density are observed corresponding to some of the phase boundaries, and conversion to the micellar phase is evidenced by the transition to optical clarity. A pseudo-binary-phase diagram has been constructed as a function of PEG concentration, and comparison with the phase diagram of lysopalmitoylphosphatidylcholine as a function of water content [Arvidson et al. (1985) Eur. J. Biochem. 152, 753-759] indicates that PEG controls the polymorphic phase behavior by reducing water activity. These results are discussed within the context of PEG-induced cell fusion.
\end{abstract}

$\mathbf{P}$ lene glycol) (PEG) ${ }^{1}$ is known to have many in teresting effects in biological systems, among these being the induction of cell fusion (Ahkong et al., 1975; Lucy, 1984). One of the primary effects by which fusion is induced is thought to be the reduction of water activity by PEG, leading to an effective membrane dehydration (Arnold et al., 1983; MacDonald, 1985). A possible mechanism by which this may take place is the modulation of the lipid phase behavior resulting from the reduction in lipid hydration. A reduction of the water content is known to favor formation of the inverted hexagonal phase in lamellar phosphatidylethanolamines (Seddon et al.,

\footnotetext{
This work has been supported in part by Grant Ma 756/2-3 from the Deutsche Forschungsgemeinschaft.

'Present address: Mass Spectrometry and Computer Unit, Chemical Pathology, Queen Charlotte's Maternity Hospital, Goldhawk Rd., London W6 OXG, U.K.
}

1984) and various natural lipid systems (Luzzati, 1968). Thus, it is possible that PEG may induce the formation of inverted phases which promote the nonlamellar lipid topology necessary for fusion. On the one hand, PEG has been shown to induce nonlamellar defects in egg phosphatidylcholine bilayers (Boni et al., 1981) and, on the other hand, to increase the phase transition temperature of dipalmitoylphosphatidylcholine (Tilcock \& Fisher, 1979). The latter is consistent with the effects of decreasing water activity, since in this system the lipid remains in a lamellar phase down to low water contents.

A partial phase diagram has recently been published for the palmitoyllysophosphatidylcholine $\left(\mathrm{C}_{16}\right.$ lyso $\left.\mathrm{PC}\right)$ /water system (Arvidson et al., 1985). At high water contents and tem-

\footnotetext{
${ }^{1}$ Abbreviations: $\mathrm{C}_{16}$ lysoPC, 1-palmitoyl-2-lyso-sn-glycero-3phosphocholine; PEG, poly(ethylene glycol); NMR, nuclear magnetic resonance.
} 